\title{
PROVEDOR DE SERVIÇOS LOGÍSTICOS - PERSPECTIVAS DO MODELO 4PL
}

\author{
LOGISTICS SERVICE PROVIDER - 4PL MODEL \\ PERSPECTIVES
}

\section{PROVEEDOR DE SERVICIOS LOGÍSTICOS - PERSPECTIVAS DEL MODELO 4PL}

\author{
Mauro Vivaldini \\ Docente da Universidade Paulista, Brasil \\ Doutor em Engenharia de Produção pela \\ Universidade Metodista de Piracicaba, Brasil \\ mavivald@gmail.com
}

\author{
Contextus \\ ISSNe 2178-9258 \\ Organização: Comitê Científico Interinstitucional \\ Editor-Chefe: Diego de Queiroz Machado \\ Avaliação: double blind review pelo SEER/OJS \\ Artigo indicado para fast-track no XXII Seminários em \\ Administração (SEMEAD 2019) \\ Recebido em 13/11/2019 \\ Aceito em 22/11/2019 \\ Versão final aceita em 24/11/2019 \\ http://dx.doi.org/10.19094/contextus.v17i3.42697
}

\begin{abstract}
RESUMO
A partir de uma abordagem teórica, esta pesquisa explora e analisa a terceirização logística, com foco específico no modelo 4PL. A intenção é saber qual é o entendimento que se tem desse provedor e apresentar os principais fatores que o caracterizam, bem como que perspectivas ele tem pela frente. Este trabalho, trazendo uma discussão do tema amparada pela teoria, contribui com uma análise de seu papel nas operações logísticas, bem como apresenta e discute os principais fatores que definem suas atividades, os pontos críticos e as perspectivas. As discussões apresentadas apontam fatores relacionados a perspectivas futuras do 4PL, servindo de base para diversas novas pesquisas, uma vez que sinalizam proposições a respeito desse modelo de prestação de serviços logísticos.
\end{abstract}

Palavras-chave: 3PL; 4PL; Terceirização; Logística; Cadeia de Suprimentos.

\section{ABSTRACT}

Based on a theoretical approach, this research explores and analyzes logistics outsourcing, with a specific focus on the 4PL model. The intention is to know how this provider is usually understood and to present not only the main factors that characterize it but also what perspectives it has ahead. This paper, while bringing a discussion of the theme supported by theory, contributes an analysis of its role in logistics operations, as well as presents and discusses the main factors that define its activities, critical points and perspectives. The discussions presented indicate factors related to 4PL's future perspectives, while serving as a basis for several new researches, since they signal propositions regarding this model of logistic service delivery.

Keywords: 3PL; 4PL; Outsourcing; Logistics; Supply Chain.

\section{RESUMEN}

Desde un enfoque teórico, esta investigación explora y analiza el outsourcing logístico, con un enfoque específico en el modelo 4PL. La intención es saber cuál es la comprensión de este proveedor y presentar los principales factores que lo caracterizan, así como las perspectivas que tiene por delante. Este documento, que presenta una discusión sobre el tema respaldado por la teoría, contribuye al análisis de su papel en las operaciones logísticas, así como presenta y discute los principales factores que definen sus actividades, los puntos críticos y las perspectivas. Las discusiones presentadas apuntan a factores relacionados con las perspectivas futuras de 4PL, que sirven de base para varias investigaciones nuevas, ya que señalan propuestas con respecto a este modelo de prestación de servicios logísticos.

Palabras clave: 3PL; 4PL; Outsourcing; Logística; Cadena de suministro. 


\section{INTRODUÇÃO}

O provedor de serviços logísticos conhecido como 3PL (Third Party Logistics) tem como foco principal executar atividades físicas ligadas ao transporte e ao manuseio e armazenagem de produtos, podendo elas ser complementadas por atividades de alto valor agregado, como comanufatura, coembalagem, crossdocking e logística reversa. Por sua vez, os provedores de 4PL (Fourth Party Logistics) são empresas que reúnem seus próprios recursos, capacidades e tecnologias e os de outros provedores para projetar e orientar cadeias de suprimento. Independentemente de possuírem ou não os meios de produção, os armazéns e caminhões, mobilizam suas competências de engenharia logística para otimizar os fluxos e selecionar os melhores provedores. Eles são, portanto, partes interessadas que coordenam as atividades entre os supridores e o cliente final em nome de seus contratantes, envolvendo por vezes outros provedores 3PL. Os provedores 4PL podem ser 3PL que diversificam sua oferta, firmas de consultoria de gestão, especialistas em cadeia de suprimentos ou mesmo empresas de serviços de Tecnologia da Informação (FULCONIS; PACHÉ, 2018; WANG; PERSSON; HUEMER, 2016; SUBRAMANIAN et al., 2016).

Segundo Hartman, Ogden e Hazen (2017), a adoção de 3PL ou 4PL é vista como forma de minimizar ou eliminar atividades que a empresa não considera competências básicas ou que entende não estarem relacionadas diretamente à atividade fim. Contudo, a empresa nem sempre tem a certeza de que essa terceirização alcançará os resultados desejados, quer reduzindo o custo, quer melhorando a qualidade e a produtividade. Para tanto, os gestores devem estabelecer um processo de análise detalhado, com informações internas e externas, precisas e completas para tomar a decisão, de forma que possam perceber as possibilidades ofertadas pelos 3PL ou 4PL, comparativamente àquilo que já executam internamente. Fato é, que conforme aqueles autores, poucas empresas têm informações completas para o processo de tomar decisões. A decisão bem embasada ou amparada por um conjunto de informações históricas tende a ser benéfica a longo prazo, mais do que uma decisão baseada em informações parciais obtidas no curto prazo.

Relativo ao modelo 4PL, pesquisa de Mehmann e Teuteberg (2016) demonstra que ele se destaca na gestão do planejamento de transporte cooperativo, redução do trabalho redundante e minimização de atrasos no fluxo de informações. Entretanto, a pesquisa ressalva novos questionamentos a respeito de sua atuação, não só sobre aproveitar sinergias que os provedores podem oferecer, mas também sobre possíveis sobrepreços ou taxas administrativas que 
poderiam ser evitadas. Para os autores, ainda não aparecem com muita clareza as vantagens oriundas da adoção do modelo; é preciso entender, na verdade, que aqueles provedores tendem a não gerar sobretaxas ou sobrepreços. A pesquisa também demonstra haver insegurança dos gestores contratantes quanto ao modelo, independentemente dos resultados obtidos.

Considerando as oportunidades de estudos relativas ao tema (CEZANNE; SAGLIETTO, 2015), este estudo foca no modelo 4PL, pois o momento literário apresenta questionamentos a respeito, como os citados anteriormente por Mehmann e Teuteberg (2016), e esse modelo de gestão terceirizada da logística consiste em proposta ainda em evolução, confundindo-se com o 3PL (FULCONIS; PACHÉ, 2018; LIEB; LIEB, 2015; BATARLIENÉ; JARAŠŪNIENÉ, 2017). Portanto, partindo da intenção de saber qual é o entendimento que vem sendo dado pela literatura a respeito dos 4PL, o estudo faz uso de uma revisão literária e apresenta as principais características e perspectivas desse modelo de negócio.

Embora a literatura a respeito dos 3PL tenha rapidamente percebido esse movimento, as características dessa nova geração de provedor, marcado pela desmaterialização dos serviços logísticos, permanece em grande parte desconhecido e pouco explorado (FULCONIS; PACHÉ, 2018; LIEB; LIEB, 2015). Têm sido sugeridos novos estudos a respeito do modelo 4PL (CLEOPHAS et al., 2019; LANGLEY, 2019; LIEB; LIEB, 2015; RODRIGUES et al., 2018), não apenas sobre as suas atividades e a consolidação na prestação de serviços, mas também sobre o impacto das novas tecnologias no comportamento comercial, sinalizando o momento como oportuno para uma melhor análise de suas perspectivas, tanto para estabelecer um entendimento de mercado, quanto para direcionar suas próprias estratégias futuras.

\section{METODOLOGIA}

Este estudo é caracterizado como um estudo teórico, realizado a partir da revisão da literatura (TRANFIELD et al. 2003) em artigos relativos ao tema 4PL (Fourth Party Logistics), e conduzido conforme protocolo de pesquisa descrito no Quadro 1.

Quadro 1 - Protocolo de pesquisa
\begin{tabular}{|l|l|}
\hline $\begin{array}{c}\text { Protocolo } \\
\text { de } \\
\text { pesquisa }\end{array}$ & \\
\hline $\begin{array}{l}\text { Bases de } \\
\text { dados }\end{array}$ & $\begin{array}{l}\text { Scopus; ScienceDirect (Elsevier); Emeraldinsight (Emerald); Wiley Online Library (Wiley); } \\
\text { Taylor \& Francis Online (Taylor \& Francis); Sagepub (Sage Journals); IEEE Xplore Digital } \\
\text { Library (IEEE); e Springer Link (Springer) }\end{array}$ \\
\hline $\begin{array}{l}\text { Tipo de } \\
\text { publicação }\end{array}$ & Somente “Journals” revisados por pares \\
\hline
\end{tabular}

(CONTINUA) 


\section{(CONTINUAÇÃO)}

\begin{tabular}{|l|l|}
\hline Linguagem & Somente artigos em português e inglês \\
\hline $\begin{array}{l}\text { Período } \\
\text { pesquisado }\end{array}$ & De 2010 a 2019 \\
\hline $\begin{array}{l}\text { Campo de } \\
\text { pesquisa }\end{array}$ & Títulos, resumos e palavras chaves \\
\hline $\begin{array}{l}\text { Termos de } \\
\text { pesquisa }\end{array}$ & $\begin{array}{l}\text { (TITLE-ABS-KEY (4PL) ANDTITLE-ABS-KEY (“Fourth Party Logistics”) ORTITLE-ABS- } \\
\text { KEY (4PL) ORTITLE-ABS-KEY (FourthANDPartyANDLogistics) ORTITLE-ABS-KEY } \\
\text { Quarteirização) }\end{array}$ \\
\hline $\begin{array}{l}\text { Critério de } \\
\text { inclusão }\end{array}$ & $\begin{array}{l}\text { Artigos que discutem ou abordam a gestão 4PL - Fourth Party logistics, ou mesmo } \\
\text { quarteirização logística }\end{array}$ \\
\hline $\begin{array}{l}\text { Critério de } \\
\text { exclusão }\end{array}$ & $\begin{array}{l}\text { Artigos que abordam terceirização logística, mas não abordam o 4PL, ou apenas cita o tema, } \\
\text { mas não discute seu papel na prestação de serviços logísticos }\end{array}$ \\
\hline $\begin{array}{l}\text { Análise } \\
\text { dos dados } \\
\text { e síntese }\end{array}$ & $\begin{array}{l}\text { Uma abordagem de análise de conteúdo foi usada para responder à pergunta da pesquisa, } \\
\text { mantendo o foco proposto. }\end{array}$ \\
\hline
\end{tabular}

Fonte: elaboração própria.

Na primeira abordagem, a pesquisa concentrou-se em artigos revisados por pares e publicados nos principais journals acadêmicos da área, sendo selecionados 85 artigos. Num segundo momento, com o intuito de melhor entender o papel deste provedor nas diferentes operações em CS, os artigos foram melhor analisados pelo autor, e deles foram selecionados 24 (conforme Quadro 2) que estavam mais atualizados com tema ou tinham relação direta com o objetivo dessa pesquisa.

Quadro 2 - Artigos Selecionados

\begin{tabular}{|c|c|c|c|}
\hline Journal Pesquisado & Artigos & Journal Pesquisado & Artigos \\
\hline 2014_north_american_3pl_ceo_study & 1 & Journal of Business Research & 1 \\
\hline 2019-3PL-Study & 1 & Journal of Modelling in Management & 1 \\
\hline Business Process Management Journal & 1 & Knowledge-Based Systems & 1 \\
\hline European Journal of Operational Research & 1 & Long Range Planning & 1 \\
\hline $\begin{array}{l}\text { GEPROS. Gestão da Produção, Operações } \\
\text { e Sistemas }\end{array}$ & 1 & $\begin{array}{l}\text { Procedia - Social and Behavioral } \\
\text { Sciences }\end{array}$ & 1 \\
\hline Industrial Management \& Data Systems & 1 & Procedia Engineering & 1 \\
\hline $\begin{array}{l}\text { International Journal of Logistics- } \\
\text { Research and Applications }\end{array}$ & 1 & $\begin{array}{l}\text { Supply Chain Management: An Int. } \\
\text { Journal }\end{array}$ & 1 \\
\hline $\begin{array}{l}\text { International Journal of Operations \& } \\
\text { Production Management }\end{array}$ & 2 & $\begin{array}{l}\text { The International Journal of Logistics } \\
\text { Management }\end{array}$ & 1 \\
\hline $\begin{array}{l}\text { International Journal of Physical } \\
\text { Distribution \& Logistics Management }\end{array}$ & 3 & Transportation Research Procedia & 1 \\
\hline $\begin{array}{l}\text { International Journal of Production } \\
\text { Economics }\end{array}$ & 2 & $\begin{array}{l}\text { Universal Journal of industrial and } \\
\text { Business Management }\end{array}$ & 1 \\
\hline
\end{tabular}

Fonte: elaboração própria.

A condução da pesquisa foi sequenciada conforme ilustra a Figura 1. No Estágio 1 (planejamento da revisão) o escopo da pesquisa foi definido, incluindo a questão de pesquisa e o protocolo de como a revisão seria conduzida. A pesquisa é concentrada na busca de material 
que discute o papel dos provedores 4PL. No estágio 2 (realização de uma revisão) foram identificados, através de bases de dados, um grupo amplo de artigos, para em seguida filtrar o material com a leitura dos resumos. Neste sentido, esse estudo incluiu apenas artigos que atenderam aos critérios completos do protocolo de pesquisa, descritos no Quadro 1 (TRANFIELD et al., 2003). Com o número final de artigos definido, iniciou-se a análise do material, organização das ideias e conceitos, entrando na classificação do que seria abordado nas discussões.

Figura 1 - Estágios para a condução da pesquisa

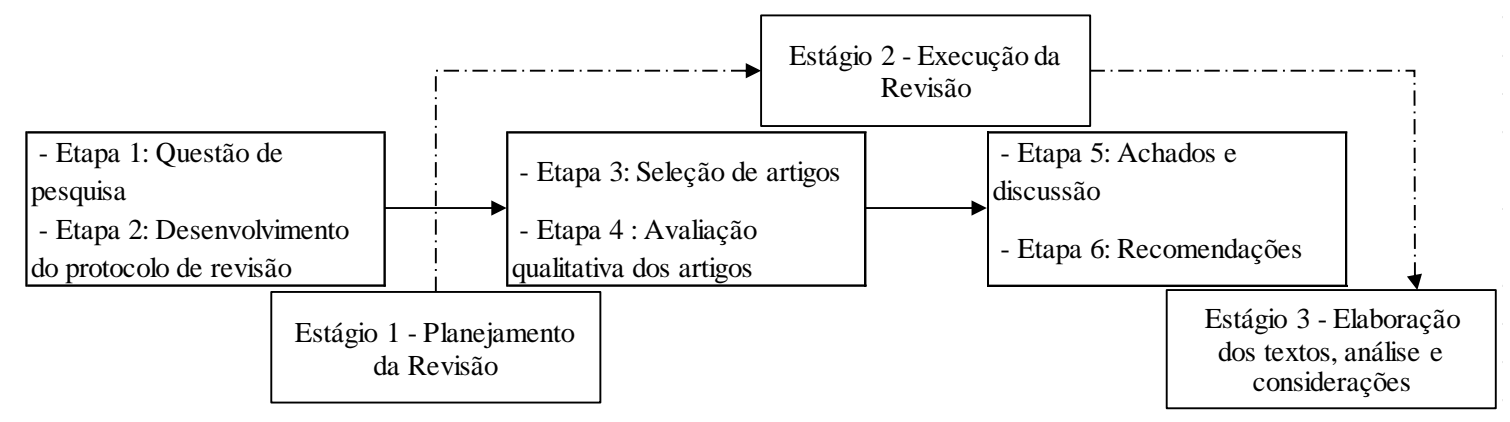

Fonte: elaboração própria.

No estágio 3 (elaboração do artigo), as principais informações a respeito do foco da pesquisa são contextualizadas e discutidas, e são apresentadas as principais ideias e proposições para pesquisas (TRANFIELD et al., 2003). Implicações gerenciais e teóricas foram destacadas nas discussões, bem como recomendações para pesquisas são sugeridas.

\section{TERCEIRIZAÇÃO LOGÍSTICA - 3PL}

Entre fazer ou terceirizar existe uma variedade de estratégias que se relaciona com as duas decisões (NORDIGÅRDEN et al., 2014). A terceirização tende a ocorrer para complementar a própria produção interna ou uma atividade não dominada pela empresa, na expectativa seja de otimizar a utilização da capacidade das próprias plantas da empresa, seja de repassar uma produção menos eficiente em termos de custos ou mesmo como uma opção quando necessária. Na produção interna, a terceirização é complementar, mantém as competências e evita o risco de paralização. Os autores alertam os gestores a pensarem duas vezes antes de implementar uma estratégia de terceirização, principalmente no caso de as capacidades internas estarem completamente tomadas, pois para eles é importante ter uma visão dinâmica da terceirização, considerando a necessidade de flexibilidade (estratégica e operacional) e de manter as competências complementares internamente. Neste caso, esta 
afirmação faz sentido em um mercado de fornecedores não desenvolvido, cujos componentes considerados para terceirização são específicos e sujeitos a falhas de fornecedores, ou quando o terceirizado tem pouca experiencia com o produto. Uma segunda opção é adotar uma estratégia mista, com produção interna e uma paralela para proteger ou mesmo desenvolver o terceirizado para necessidades especificas. Ainda, uma outra opção é uma estratégia mista que mantém a maior parte da produção interna, e parte terceirizada para equilibrar picos de demanda, ou mesmo terceirizar produção não padronizada que não complementa produção em grande escala. Assim, a adoção de uma estratégia mista melhora a flexibilidade para as empresas que contemplam a terceirização.

No entanto, como alerta Vivaldini (2015), é importante lembrar que cada decisão se relaciona a situação individual de cada empresa. Não muito diferente do processo produtivo, a terceirização logística também tem suas individualidades, mas na maioria das vezes se caracteriza pela falta de expertise no tipo de operação e nos altos investimentos em ativos relacionados a transporte e armazenagem necessários à empresa.

Diferentemente da ideia de terceirização mista, em que existe uma produção interna e outra externa, a terceirização logística tem suas particularidades, e como colocado por Huo et al. (2015) o relacionamento desenvolvido junto aos provedores influencia e tem papel de destaque na decisão, pois os serviços têm valores implícitos nem sempre mensuráveis, como nas especificações de um produto. Os gestores que adotam a terceirização logística devem considerar a importância de se avaliar que tipo de dependência caracteriza suas relações com esses provedores. Portanto, a pesquisa destes autores, sugere que desenvolvam confiança e compartilhem relacionamentos baseados em valores com seus provedores, e mantenham relações de cooperação a longo prazo. Caso os usuários dos 3PL investem em ativos específicos na terceirização, eles devem identificar e desenvolver valores compartilhados com seus provedores para diminuir o oportunismo e impedir o término de relações comerciais. Neste aspecto, os efeitos da dependência e do compromisso indicam que os relacionamentos baseados em recursos e valores são importantes para a terceirização logística. Por outro lado, as empresas devem perceber os recursos investidos pelos 3PL na terceirização e tentar controlar os riscos e desvios apresentados.

Os efeitos da terceirização ocorrem nos níveis de serviços (controlados por indicadores chave) os quais permitem às empresas posicionarem corretamente suas atividades de terceirização e melhorarem o desempenho. Nesta linha, como colocado por Vivaldini e Pires (2013), ocorre a terceirização básica, cuja relação se dá por contratações pontuais, ou de pouco 
valor agregado, como transporte ou guarda de produto. Além disso, há as terceirizações avançadas ou personalizadas, em que o 3PL desempenha papel central nas operações logísticas, indo além de transporte e guarda de produtos, ao trabalhar em conjunto com o contratante para aprimorar os indicadores e a qualidade dos serviços.

Hsiao et al. (2010), num estudo quanto às decisões que conduzem a terceirização logística, coloca que (1) a decisão de terceirização logística está relacionada à especificidade do recurso, à proximidade do núcleo operacional e à complexidade da cadeia de suprimentos. Quanto menor o investimento atual da empresa em ativos de logística, maior a probabilidade de terceirização da atividade. Quanto menor a atividade do negócio principal, maior a probabilidade de uma atividade ser terceirizada. Além disso, também, quanto maior a complexidade da cadeia de suprimentos, maior a probabilidade de uma atividade ser terceirizada. Para ele, (2) as atividades de logística em diferentes níveis são terceirizadas por diferentes motivos, pois requerem uma visão sobre o custo de transação, especificidade de ativos e a complexidade da cadeia de suprimentos, como também, com menor relevância, (3) a incerteza da medição do desempenho e a estratégia de logística podem ter influência.

Considerando a importância da performance dos serviços logísticos, Gerbl, Mcivor e Humphreys (2016) destacam a importância de monitorar a terceirização, e Selviaridis (2016) aponta que o desempenho e os resultados obtidos pelos 3PL têm forte dependência do próprio cliente e de subcontratados. Neste sentido, a avaliação dos 3PL via KPIs (Key Performance Indicators) devem ser acompanhados de especificações explicitas e claras, especialmente aquelas exigidas pelos clientes e seus parceiros da cadeia de suprimentos (CS), podendo com isso minimizar sua contestabilidade. Estes autores alertam a respeito dos efeitos nocivos dos KPIs na relação com os clientes e sustentam a importância de os 3PL trabalharem esta questão com seus clientes e subcontratados, mantendo sempre um processo de revisão contínua. Eles sugerem que é preciso caminhar para um gerenciamento do desempenho amparado por coleta e análise de dados, sejam eles adquiridos por sistemas de informação ou recursos humanos dedicados, podendo por meio disso, evitar que os envolvidos nas operações fomentem uma cultura de culpa mútua por falhas de serviço. Neste caso, sugere-se que o 3PL assuma essa tarefa, pois ela aumenta a transparência em relação à alocação de ganhos e riscos, reforça o nível de equidade distributiva, já que isso é percebido pela parte contratante.

O 3PL tradicionalmente cumpre a função de provedor logístico, organizando o armazenamento, bem como a preparação de pedidos e entrega final de produtos para seus clientes. Está posicionado para organizar os recursos logísticos e, assim, ajudar as CS a alcançar 
economias substanciais de escala e escopo. No entanto, o 3PL testemunhou o surgimento de uma categoria inovadora que incomoda os modelos de negócios anteriores: a quarteirização logística, representado por cum provedor 4PL. Atuam como orquestradores, organizam e coordenam fluxos de produtos para embarcadores, mobilizando as capacidades logísticas de um grande número de empresas subcontratadas.

\section{FOURTH PARTY LOGISTICS - 4PL}

Fulconis e Paché (2018) defendem que o provedor 4PL normalmente complementa o papel do provedor 3PL. Seu papel consiste em conceber e vender soluções logísticas personalizadas, por meio da mobilização de recursos internos, ou através de transportadores, de armazéns, e demais subcontratados que complementem as atividades necessárias para as operações logísticas. Portanto, é possível e, às vezes, até desejável que ele monte uma proposta de serviço, sem necessariamente possuir ativos físicos muito caros. Sabe-que, em operações logísticas, diversos ativos são necessários para conduzir as atividades: ativos físicos (semirreboques, tecnologia da informação, equipamentos embarcados), ativos locais (armazéns, plataformas), ativos humanos (competências técnicas e gerenciais), ativos de reputação (marcas, identidade visual) e ativos organizacionais (procedimentos, rotinas). Este é o caso do 3PL, mas não está na essência do modelo 4PL, que afirma ser "livre de ativos". Na verdade, o provedor 4PL cria legitimidade no mercado com base em sua especialidade em coordenação das operações. Sua especialidade está na orquestração de ativos mantidos por todos os parceiros.

Como citado por Wang, Persson e Huemer (2016), a dimensão da informação é um elemento importante da oferta deste provedor, porque sua função requer a perfeita rastreabilidade dos fluxos, juntamente com o monitoramento em tempo real do desempenho dos parceiros envolvidos nas operações contratadas. Como apontado por Vivaldini (2015), as capacidades de TI (tecnologia da informação) parecem ser um importante diferencial para os fornecedores 4PL, sendo fundamental para agilizar o tempo de resposta. Tendo conhecimentos na gestão de fluxos físicos via fluxos de informação, e expertise para agrupar recursos complementares, esse provedor se afasta das atividades "clássicas" de prestação de serviços logísticos que giram em torno da implementação específica dos fluxos. 
O 4PL representa uma nova geração de provedor logístico, marcada pelo gerenciamento eficaz de dimensões tanto organizacionais (controles e fluxos organizados) quanto operacionais (identificação de parceiros). Assim, o 4PL pode vender soluções tipo "chave na mão", como coordenar atividades de transporte, manuseio, armazenamento, subcontratação, embalagem etc. Por isso, se difere do tradicional 3PL, cuja proposta no mercado está vinculada à propriedade de recursos materiais, comumente representados pelos meios de armazenamento e uma frota de veículos. O desenvolvimento dos 4PL foi impulsionado pela capacidade de responderem aos requisitos de agilidade, assegurando a capacidade das CS de suportar mudanças frequentes e constantes causadas pelo ambiente externo. Eles devem ter uma forte capacidade na implementação de soluções, reconfigurando quando necessário, as operações logísticas que dirigem (BHATTI; KUMAR; KUMAR, 2010; DIRCKSEN; MAGNIN, 2017).

$\mathrm{O}$ fator preponderante que define o 4PL é que eles realizam o planejamento e a coordenação dos fluxos operacionais, projetando tanto a arquitetura de uma CS quanto os sistemas de informação relacionados. Também, como colocado Fulconis e Paché (2018) o provedor 4PL pode oferecer soluções logística em escala global, baseando-se em sua capacidade de criar conexões entre os fornecedores e clientes. Aqueles que atendem grandes varejistas e organizações industriais adquirem muitos diferenciais, e por isso podem se posicionar como arquitetos logísticos com a capacidade de construir, desmontar e reconstruir uma cadeia de suprimentos, coordenando-a segundo as especificações contratadas. Atuando como um parceiro exclusivo o 4PL concilia as necessidades de várias empresas, podendo repassar a vantagem em termos de negociação e networking. Sua atuação é expressa em níveis operacionais variados, como em armazenamento, transporte e entrega final. Para isso, faz uso de ferramentas de monitoramento em tempo real e rastreabilidade das operações, condição imprescindível para ter flexibilidade. Com isso, ele desenvolve conhecimento cumulativo por atuar com diferentes problemas em distintas CS.

A capacidade de soluções do 4PL envolve identificar as melhores alternativas para o transporte, gestão de inventário, localização e operação de armazéns etc., relacionada a uma CS. Sua tarefa é criar valor através dos agentes da CS, expressa pela sua capacidade de organizar recursos e competências de maneira responsiva, ofertando serviços versáteis, articulado por suas habilidades complementares na rede de relacionamento. Eles devem ter uma plasticidade operacional, sendo essa a tendência atual para responder a uma economia em constante movimento, com resiliência para se adaptar a um ambiente cada vez mais turbulento.

Para otimizar a eficiência de suas operações logísticas, os 4PLs têm de controlar os riscos durante as operações, considerando sua importância na gestão do nível de qualidade do 
serviço logístico. Muitos riscos potenciais estão associados às atividades logísticas, podendo surgir de erros subjetivos, como informações incorretas de entrega, ou advindos de falhas funcionais. Outros podem ser causados por erros objetivos, como danos às mercadorias ou impossibilidade de garantir a entrega no prazo devido ao mau tempo ou às condições das estradas. Independente do risco, todos podem causar perda de lucro tanto para as empresas de logística quanto para os clientes. Para melhorar a eficiência das operações, o 4PL precisa que seus parceiros invistam em equipamentos, tecnologia de monitoramento em tempo real e força de trabalho qualificada. Esses investimentos tendem a reduzir os riscos no processo logístico. (HUANG et al., 2019).

Wang, Persson e Huemer (2016) abordam a questão da colaboração nas operações logísticas, destacando que para isso o uso de TI é importante para promover resultados, e o 4PL é um agente com essas competências e pode atuar como um integrador. No entanto, eles não podem atuar de forma passiva, pois desenvolvem os padrões e a oferta de serviços, bem como incentivam a inovação e a mudança na rede em que se relaciona. Considerando, no caso, que o 4PL tendem a não se basearem em ativos, utilizando os 3PLs para acessar os recursos exigidos para as operações da logística física. Essa abordagem favorece o posicionamento do 4PL nas questões funcionais e sistêmicas de colaboração.

Huang et al. (2015) e Dircksen e Magnin (2017), a respeito do impacto da quarteirização no desempenho das entregas, avaliam a colaboração entre um gestor 4PL e seus transportadores na intenção de entender por meio de simulações de cenários o comportamento dos transportadores na distribuição de cargas e definição de tarifas. Um dos fatores surgido como preponderante para a gestão do 4PL foi a coerência na definição das tarifas, criando um ambiente justo aos transportadores. Essa relação traz como consequência melhor desempenho e resultados ao cliente contratante dos serviços do 4PL, segundo eles, em estudo prático a melhoria chegou em até $29 \%$ de benefício nos custos. No entanto, os autores salientam que em uma relação típica de transporte entre 4PL e fabricante, o 4PL atua como um parceiro neutro para gerenciar os transportadores do fabricante e não intervém no processo de cobrança entre eles. No que diz respeito à consolidação de cargas de diferentes fabricantes, o frete deve ser faturado como um transportador. Neste caso, o 4PL teria de intervir no processo de cobrança para distribuir os custos aos fabricantes, o que pode ser visto como um comprometimento a sua posição neutra.

Estudos de Saglietto (2013) e Cezanne e Saglietto (2015) apontam que o 4PL é reconhecido pela experiência e reputação, geralmente baseadas em três conceitos-chave: a neutralidade, a garantia de opções na oferta de serviços e potencial humano a serviço dos 
clientes. Neutralidade significa atuar de forma isenta e correta, independentemente de qualquer outra empresa logística. Deve ser livre para oferecer soluções imparciais e estabelecer parcerias externas. Apresentar uma oferta abrangente, buscando e avaliando opções (1PL, 2PL, 3PL) em nome de seus clientes, que serão incorporados nas operações com base na experiência e capacidade de execução. Ter foco e se concentrar em encontrar os provedores que podem contribuir de forma eficaz e econômica para melhorar a logística da empresa.

4PLs atuam como interface e um único ponto de contato entre as partes, compartilham os riscos com os clientes e oferecem serviços múltiplos, apresentam novas técnicas e suporte constante. O capital humano do 4PL é representado pelo conhecimento e habilidades de seus profissionais, podem atuar como consultores contribuir para estratégias que melhoram o desempenho das operações logísticas, devem ser criativos, no sentido de estarem em constante busca de novos conceitos e técnicas organizacionais para encontrar oportunidades para seus clientes.

Alguns novos aspectos vêm caracterizando a diversidade de serviços ofertados pelos 4PL, como no caso de serviços relacionados a regras e legislação local necessária nas operações logísticas (RODRIGUES et al., 2018). Também, como mencionado por Rahman et al. (2017) que entende a importância dos 4PLs serem empresas caracterizadas por operações multinacionais, pois isso favorece as empresas e melhora o nível de serviço, além de serem mais fortes nos relacionamentos com governos e instituições para desenvolver o setor. Ou, numa visão de avanço tecnológico, como citado por Langley (2019) que destaca a importância dessas empresas avançarem em desenvolvimentos via "Blockchain".

Por sua vez, Cleophas et al., (2019) citam a importância de avançar a relação colaborativa com os clientes, como no caso da entrega urbana, cuja opção seria que a primeira perna do frete dentro da cidade poderia ser realizada por caminhões convencionais, enquanto a última milha até o destinatário poderia ser operada por veículos ecológicos ou bicicletas de carga, como também ter vários fornecedores trabalhando juntos na mesma CS, potencialmente compartilhando pedidos e infraestrutura. Shi et al. (2016) citam que é possível agregar a prestação de serviços de compras para os clientes, também. Numa perspectiva mais ampla, Subramanian et al. (2016) sugerem o incentivo aos clusters industriais via governo, que assumiria a responsabilidade de construir a integração com o 4PL, atraindo empresas para participar, ajudando as empresas dentro dos grupos a obter benefícios mútuos. 


\section{ANALISANDO AS PERSPECTIVAS DO 4PL A PARTIR DA TEORIA}

Com base nas abordagens apresentadas, a Figura 2 ilustra a visão evolutiva dos provedores para a terceirização de serviços logísticos. Observa-se que:

a) Do ponto de vista do próprio operador - há as possibilidades de ascensão e evolução de seus serviços, segundo as principiais variáveis (Complexidade da CS, Investimentos, Probabilidade de terceirizar) que influenciam seu posicionamento no mercado, seja ele 1PL (oferta de 1 serviço básico, como transporte ou armazém), 2PL (oferta de 2 serviços básicos, combinados ou não), 3PL (oferta de serviços logísticos para um grupo de atividades), ou 4PL (coordenação e estruturação de operações logísticas na RS).

b) Quanto à visão que o mercado pode estabelecer - baseando-se nas limitações e características de cada tipo de negócio ou empresa, alinhada com a decisão estratégica que adotem, a escolha do tipo de provedor se relaciona com a complexidade da cadeia e aos investimentos necessários para realizar as operações logísticas. Assim, pode-se dizer que a probabilidade de se escolher um modelo mais completo na oferta de serviços, como no caso do 3PL ou 4PL, tem relação direta com a disposição da empresa em investir ou não e de assumir as operações ou não com todos os nós existentes em sua CS.

Figura 2 - Provedores de serviços logísticos

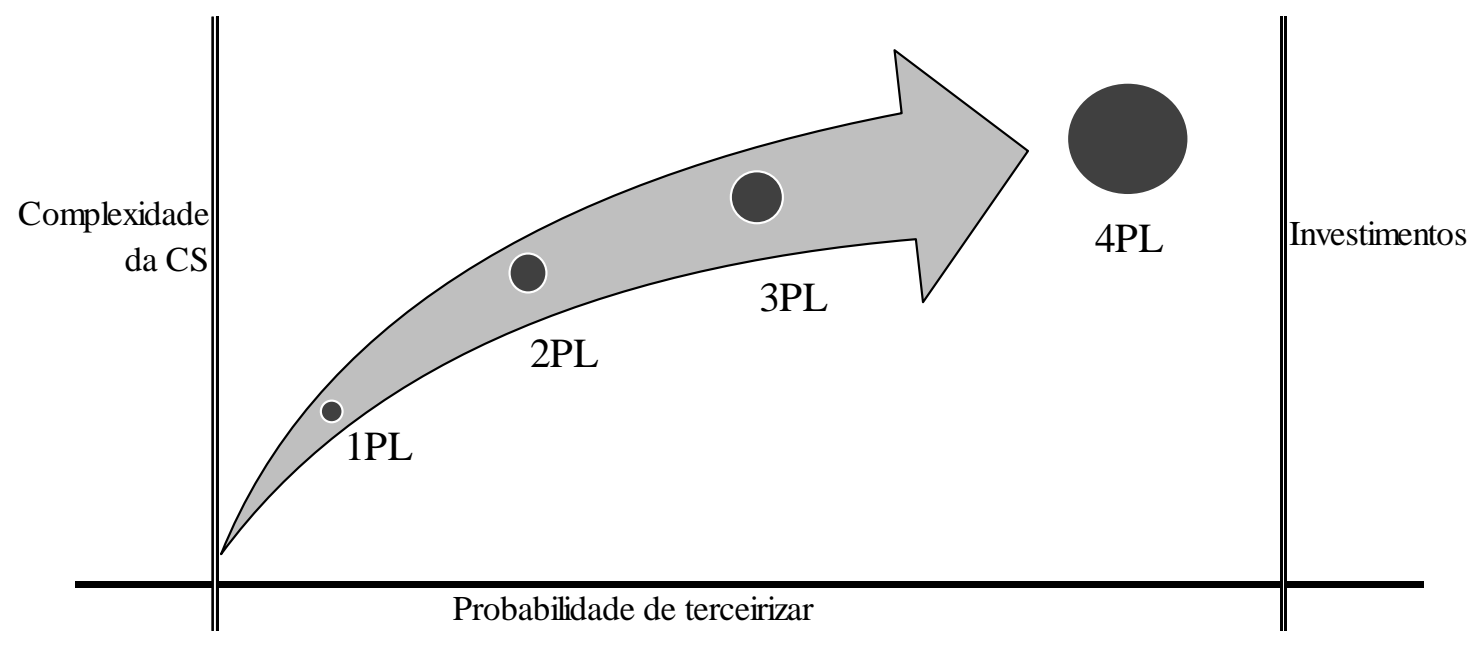

Fonte: elaboração própria.

Portanto, a probabilidade de terceirização de um único serviço no modelo 1PL está relacionada a complexidade e investimentos baixos, uma vez que essa atividade exige pouca especialização e existe grande oferta no mercado. Para o modelo 2PL aumentam-se a 
complexidade e os investimentos, porém a oferta é para atividades padrão (armazenagem e transporte) com muitos provedores disponíveis para executá-las. Já o 3PL possui uma gama de oferta de serviços ofertados, e à medida que a empresa necessita de mais atividades, maior serão a complexidade e os investimentos. Considerando o escopo de atividades e capacidade de prover serviços, incluindo a gestão dos terceiros, o modelo 4PL se apresenta com maior versatilidade para atender às demandas da CS, consequentemente deve estar preparado para tarefas com alta complexidade que exigem infraestrutura e tecnologia, ampliando os investimentos para a execução.

Complementando a Figura 2, a Figura 3 apresenta o 4PL como provedor capaz de agrupar todas as atividades dos demais para atuar como um articulador logístico na CS de seu cliente. Neste sentido, formaliza a relação com o cliente, costumeiramente a empresa foco da CS, oferecendo conhecimento em projetos e operações, capacidade de organização e planejamento de diferentes atividades logísticas, sejam elas realizadas por eles ou por outros provedores contratados. Desta forma, é uma organização que assume o papel de liderança na coordenação dos fluxos logísticos tanto a montante, quanto a jusante, onde os fornecedores e o cliente final representam os agentes envolvidos nesta prestação de serviços. Ressalva-se, neste contexto, que o 4PL atua em nome de seu cliente, zelando por resultados contratados e com o compromisso de fomentar melhorias que reflitam ganhos operacionais, sejam eles qualitativos ou financeiros.

Figura 3 - Estrutura de atuação do 4PL em Cadeias de Suprimentos

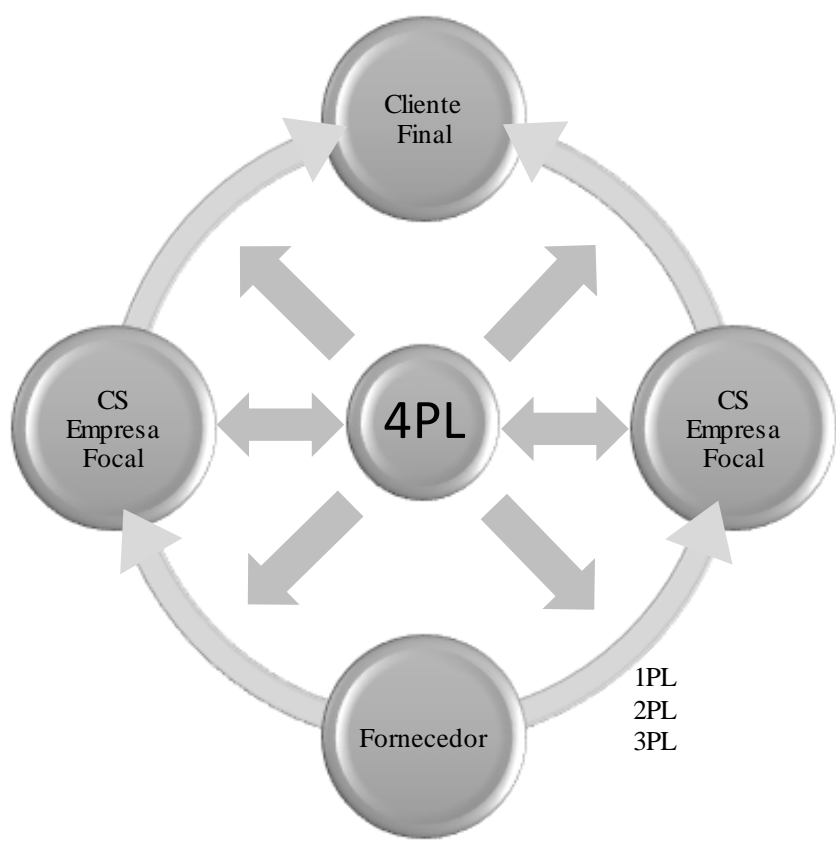

Fonte: elaboração própria. 
O 4PL se caracteriza pela capacidade de atuar em diferentes frentes para seus clientes. Ele pode agir como um contratado para um grupo de atividades, ou mesmo para toda a coordenação da CS. Atrelado a este escopo com proporções ampla, ele deve ter a competência e capacidade para articular e integrar os diferentes prestadores (1PL, 2PL e 3PL) para otimizar recursos na execução dos serviços, e assim favorecer só custos nas cadeias de seus clientes.

O escopo de atividades que podem ser cobertas pelo provedor no modelo 4PL são inúmeras, considerado o aspecto de ter a capacidade para se apoiar nos outros modelos de provedores. O Quadro 3 descreve as principais atribuições citadas na teoria, bem como, estabelece, por meio de uma análise do material pesquisado, os pontos críticos e as perspectivas que têm sido discutidas para esse modelo de prestação de serviço logístico.

Quadro 3 - Perspectivas do modelo 4PL para provedores de serviços logísticos

\begin{tabular}{|c|c|c|}
\hline Atividades & Pontos críticos & Perspectivas \\
\hline $\begin{array}{l}\text { Controle e Organização dos } \\
\text { fluxos logísticos }\end{array}$ & Livres de ativos ou não & $\begin{array}{l}\text { Criar valores } \quad \text { implícitos no } \\
\text { relacionamento e no serviço ofertado }\end{array}$ \\
\hline Redução de trabalho redundante & Também podem ser 3PL & Controlar Riscos das operações \\
\hline $\begin{array}{l}\text { Identificação, Mobilização e } \\
\text { orquestração de Terceiros }\end{array}$ & $\begin{array}{l}\text { Manter as Competência de seus } \\
\text { recursos humanos }\end{array}$ & $\begin{array}{l}\text { Se envolver em serviços relacionados } \\
\text { a legislação }\end{array}$ \\
\hline $\begin{array}{l}\text { Melhorar e minimizar atrasos de } \\
\text { informações }\end{array}$ & $\begin{array}{l}\text { Ter taxas administrativas } \\
\text { contratual }\end{array}$ & stão colaborativa \\
\hline $\begin{array}{l}\text { Projeto e Planejamento de } \\
\text { atividades logísticas }\end{array}$ & $\begin{array}{l}\text { Gerenciar e manter nível de } \\
\text { serviço }\end{array}$ & $\begin{array}{l}\text { Conhecimento cumulativo por atuar } \\
\text { com diferentes problemas em distintas } \\
\text { CS }\end{array}$ \\
\hline $\begin{array}{l}\text { Monitoramento em tempo real } \\
\text { via TI }\end{array}$ & $\begin{array}{l}\text { Neutralidade } \\
\text { comercial) }\end{array}$ & $\begin{array}{l}\text { 4PL multinacional favorece } \mathrm{o} \\
\text { segmento }\end{array}$ \\
\hline Agente integrador na CS & Não se expor a sobrepreços & Blockchain \\
\hline Oferecer opções de serviços & $\begin{array}{l}\text { Incentivar investimentos dos } \\
\text { parceiros }\end{array}$ & $\begin{array}{l}\text { Coordenar as atividades logísticas } \\
\text { clusters industriais }\end{array}$ \\
\hline Compras - Fornecimento & Solução Global & $\begin{array}{l}\text { Criar valor via agentes da CS } \\
\text { (fornecedores e cliente final) }\end{array}$ \\
\hline
\end{tabular}

Fonte: elaboração própria.

Considerando o fato de que este modelo, diferente do 3PL, ainda não se consolidou no mercado, até porque o próprio 3PL vem surgindo como um agente capaz de realizar o papel do 4PL, a teoria estudada aponta diversas questões a respeito da extensão de seus serviços e seu avanço no mercado de prestação de serviços logísticos. Neste sentido, seguem considerações a respeito dos fatores apontados no Quadro 3: 
a) Se devem ou não serem organizações livres de ativos é um ponto tido como crítico, uma vez que o princípio do 4PL reside na inteligência logística e não em seus ativos. Porém, os estudos sinalizam que ter os ativos ou parte deles favorece a captação de clientes. Essa pode ser a razão e a explicação do avanço do 3PL para o modelo 4PL.

b) A preocupação das empresas quanto à gestão de risco nas CS tem avançado e não será diferente nas relações com seus provedores logísticos. Portanto, espera-se que esses provedores demonstrem estruturas para o controle e mitigação de riscos das operações.

c) Considerando que a competência do 4PL está na capacidade de criar soluções por meio de sua experiência, sua equipe se revela um ativo fundamental para o sucesso dos negócios, sendo um desafio mantê-los na organização. Neste aspecto, um serviço que vem sendo considerado no escopo para 4PL é o entendimento sobre legislações relativas aos movimentos de produtos entre estados, ou mesmo países. Esta atividade, por sua vez, também, concentra-se no conhecimento dos recursos humanos que o provedor dispõe. Assim, percebe-se que o 4PL com estrutura ou alianças multinacionais gera credibilidade, favorece as relações comerciais e institucionais, motiva equipe interna e favorece a disseminação de soluções.

d) $\mathrm{O}$ avanço de práticas colaborativas na CS, obriga o 4PL a dominar seus conceitos e fundamentar seus negócios em relações fortes amparadas pela confiança e nível de serviço, independentemente de serem suportadas por mecanismos formais ou não. Para tanto, suas taxas administrativas devem refletir os acordos pactuados, e devem ser respeitados, repassando ao cliente quaisquer benefícios advindo de ganhos operacionais, e não se expondo a tentação de eventuais sobrepreços. Lembrando também, que sua postura deve refletir posições imparciais ou neutralidade (operacional e comercial).

e) Um dos fundamentos do 4PL é demonstrar que sua competência favorece as operações logísticas de seu cliente, e isso deve estar amparado por indicadores que gerenciem e mantenham o nível de serviço acordado, servindo de instrumento relacional entre ele, o cliente e todos os agentes da CS. Também sua postura deve demonstrar iniciativas constantes de melhoria, por onde repliquem o conhecimento e as experiencias que obtém nas operações em distintas CS.

f) No campo tecnológico, já que um de seus diferenciais é oferecer mecanismos que favoreçam as comunicações e troca de informação, avançar em soluções amparadas 
pela tecnologia do "Blockchain" será um desafio que estes provedores terão pela frente.

g) O 4PL deve ter competência para manter parceiros com capacidade para investimentos permanentes, sendo necessário para isso, que consigam gerar valor nas soluções não só para os clientes como para os demais provedores envolvidos nas operações. Neste sentido, é preciso que caminhem para soluções abrangentes, cuja desafio resida em redes de suprimentos ampliadas, como o caso de clusters industriais, ou adensamentos incentivados ou não por entidades governamentais.

\section{CONSIDERAÇÕES FINAIS}

Este trabalho, com foco específico na prestação de serviço logístico por meio do 4PL, traz uma discussão do tema amparada pela teoria, contribui com uma análise de seu papel nas operações logísticas em CS, bem como apresenta e discute os principais fatores que definem as atividades, os pontos críticos e as perspectivas para esse serviço. Portanto, o estudo fortalece o conhecimento a respeito desse agente ao caracterizá-lo conceitualmente na literatura, respeitando, é claro, todas as limitações oriundas de um estudo teórico e impostas pelo número restrito de material pesquisado, além de ser uma pesquisa com foco bem restrito e fechado.

Independentemente das limitações, o estudo demonstra avanços para a teoria ao sintetizar diversos fatores que vêm influenciando o provedor, os quais foram chamados pelo estudo de perspectivas para o modelo 4PL. Também, foi possível abstrair desta pesquisa considerações capazes de contribuir para para os gestores da área. Ou seja, suas implicações práticas estão relacionadas à importância desse modelo de negócio em construir e valorizar os relacionamentos criando soluções por meio dos serviços ofertados. Neste sentido, as novas tecnologias disruptivas que exigem muitas conexões, permitem compartilhamento e se apoiam em soluções via plataformas são opções para esse modelo de negócio e podem ser instrumentos para criar novos serviços.

As discussões apresentadas no capítulo anterior servem como base para diversas novas pesquisas, uma vez que sinalizam proposições a respeito do modelo de prestação de serviços logísticos em foco. Portanto, pesquisadores que estudam o tema têm alguns insights capazes de fomentar diferentes estudos a respeito. Neste sentido, cumpre-se a função desse trabalho, por 
ser um estudo teórico, de servir como instrumento capaz de fomentar ideias ou mesmo direcionar caminhos a novas pesquisas, tais como:

a) A posição de que o 4PL, tradicionalmente apontado na literatura como empresa livre de ativos, ainda é válida?

b) Como pode ser diferenciado o 3PL, que também atua nesse modelo?

c) Quais as razões de os 4PLs não conseguirem manter sua mão de obra especializada?

d) Como o 4PL poderia sobreviver sem depender de taxas administrativas cobradas de seus clientes?

Pontos de interesse do mercado são os riscos das operações e os serviços relacionados a leis, para os quais esses provedores podem direcionar esforços e buscar especialistas para levar soluções e proposições a seus clientes, de preferência nos mesmos moldes de aplicações compartilhadas. Inclusive essa visão de atuar com compartilhamento pode se tornar um nicho para estes provedores, uma vez que a expansão dos conceitos de rede de suprimentos, em que se conectam diversos e diferentes agentes e negócios similares, tem um universo de oportunidades. Compete, portanto, aos 4PL provocarem ações e buscarem soluções que proporcionem valores e resultados às empresas que estejam dispostas a atuar com compartilhamento.

\section{REFERÊNCIAS}

BATARLIENĖ, N.; JARAŠŪNIENĖ, A. 3PL Service Improvement Opportunities in Transport $\begin{array}{lllllll}\text { Companies. Procedia Engineering, n. 187, p. } & 67-76, & \end{array}$ <https://doi.org/10.1016/j.proeng.2017.04.351>

BHATTI, R. S.; KUMAR, P.; KUMAR, D. Analytical modeling of third-party service provider selection in lead logistics provider environments. Journal of Modelling in Management, v. 5, n. 3, p. 275-286, 2010. <http://dx.doi.org/10.1108/17465661011092641>

CEZANNE, C.; SAGLIETTO, L. Redefining the boundaries of the firm: the role of 4PLs. The International Journal of Logistics Management, v. 26, n. 1, p. 30-41, 2015. <https://doi.org/10.1108/IJLM-06-2012-0054>

CLEOPHAS, C.; COTTRILL, C.; EHMKE, J. F.; TIERNEY, K. Collaborative urban transportation: Recent advances in theory and practice. European Journal of Operational $\begin{array}{llllll}\text { Research, } & \text { Volume 273, n. 3/16, p. } & 801-816, & \end{array}$ <https://doi.org/10.1016/j.ejor.2018.04.037> 
DIRCKSEN, M.; MAGNIN, G. Evaluation of synergy potentials in transportation networks managed by a fourth party logistics provider. Transportation Research Procedia, v. 25, p. 824-841, 2017. <https://doi.org/10.1016/j.trpro.2017.05.460>

FULCONIS, F.; PACHÉ, G. Supply chain monitoring: LLPs and 4PL providers as orchestrators. Procedia - Social and Behavioral Sciences, v. 238, p. 9-18, 2018. <doi.org/10.1016/j.sbspro.2018.03.002>

GERBL, M.; MCIVOR, R.; HUMPHREYS, P. Making the business process outsourcing decision: why distance matters. International Journal of Operations \& Production Management, v. 36, n. 9, p. 1037-1064, 2016. <https://doi.org/10.1108/IJOPM-04-20140192>

HARTMAN, P. L.; OGDEN, J. A.; HAZEN, B. T. Bring it back? An examination of the insourcing decision. International Journal of Physical Distribution \& Logistics Management. v. 47, n. 2/3, p. 198-221, 2017. <https://doi.org/10.1108/IJPDLM-09-20150220>

HSIAO, H. I.; VORST, J. G. A. J. V.; KEMP, R. G. M.; OMTA, S. W. F. Developing a decision-making framework for levels of logistics outsourcing in food supply chain networks. International Journal of Physical Distribution \& Logistics Management, v. 40, n. 5, p. 395414, 2010. <https://doi.org/10.1108/0960003101105284>

HUANG M.; REN, L.; LEE L. H.; WANG X. 4PL routing optimization under emergency $\begin{array}{lllllll}\text { conditions. Knowledge-Based } & \text { Systems, } & \text { n. 89, } & \text { p. } & 126-133,\end{array}$ <https://doi.org/10.1016/j.knosys.2015.06.023>

HUO, B.; LIU, C.; KANG, M.; ZHAO, X. The impact of dependence and relationship commitment on logistics outsourcing: Empirical evidence from Greater China. International Journal of Physical Distribution \& Logistics Management, v. 45, n. 9/10, p. 887-912, 2015. $<$ https://doi.org/10.1108/IJPDLM-04-2015-0109>

LANGLEY, J. J. 2019 Third-party logistics study: The State of Logistics Outsourcing Results and Findings of the 23rd Annual Study. 2019. Disponível em: <https://dsqapj1lakrkc.cloudfront.net/media/sidebar_downloads/2019-3PL-Study.pdf>. Acesso em: 05 mar. 2019.

LIEB, R. C.; LIEB, K. 3PL CEO Study: Perspectives on the current status and future prospects of the third-party logistics industry in North America: the 2014 survey. 2015. Disponível em: <www.penskelogistics.com/pdfs/2014_north_american_3pl_ceo_study.pdf >. Acesso em: 10 Jan. 2019.

MEHMANN, J.; TEUTEBERG, F. Process reengineering by using the 4PL approach: A case study on transportation processing in the agricultural bulk logistics sector. Business Process Management Journal, v. 22, n. 4, p. 879-902, 2016. <https://doi.org/10.1108/BPMJ-12-20140119>

NORDIGÅRDEN, D.; REHME, J.; BREGE, S; CHICKSAND, D.; WALKER, H. Outsourcing decisions - the case of parallel production. International Journal of Operations \& 
Production Management, v. 34, n. 8, p. 974-1002, 2014. <https://doi.org/10.1108/IJOPM-062012-0230>

RAHMAN, S.; AHSAN, K.; YANG, L.; ODGERSA J. An Investigation into critical challenges for multinational third-party logistics providers operating in China. Journal of Business Research, v. 103, p. 607-619, October 2019. <https://doi.org/10.1016/j.jbusres.2017.09.053>

RODRIGUES, A. C.; MARTINS, R. S.; WANKE, P. F.; SIEGLER J. Efficiency of specialized 3PL providers in an emerging economy. International Journal of Production Economics, v. 205, November, p. 163-178, 2018. <https://doi.org/10.1016/j.ijpe.2018.09.012>

SAGLIETTO L. Towards a Classification of Fourth Party Logistics (4PL). Universal Journal of industrial and Business Management, v. 1, n. 3, p. 104-116, 2013. <doi.org/10.13189/ujibm.2013.010305>

SELVIARIDIS, K. Who's to blame or praise? Performance attribution challenges in outsourced service provision in supply chains. Supply Chain Management: An International Journal, v. 21, n. 5, p. 513-533, 2016. <https://doi.org/10.1108/SCM-11-2015-0439>

SHI, Y.; ZHANG A.; ARTHANARI T.; LIU Y.; CHENG T. C. E. Third-party purchase: Na empirical study of third-party logistics providers in China. International Journal of Production Economics, v. 171, Part 2, p. 189-200, 2016 January. <https://doi.org/10.1016/j.ijpe.2015.08.028>

SUBRAMANIAN, N.; GUNASEKARAN, A.; PAPADOPOULOS, T., NIE, P. 4th party logistics service providers and industrial cluster competitiveness: Collaborative operational capabilities framework. Industrial Management \& Data Systems, v. 116, n. 7, p. 1303-1330, 2016. <https://doi.org/10.1108/IMDS-06-2015-0248>

TRANFIELD, D.; DENYER, D.; SMART, P. Towards a methodology for developing evidence-informed management knowledge by means of systematic review. British Journal of Management, v. 14, n. 3, p. 207-222, 2003. <https://doi.org/10.1111/1467-8551.00375>

VIVALDINI, M. Terceirização, quarteirização e primarização logística. GEPROS. Gestão da Produção, Operações e Sistemas, ano 10, n. 4, p. 21-38, 2015. <doi.org/10.15675/gepros.v10i4.1237>

VIVALDINI, M.; PIRES, S. R. I. Applying a business cell approach to fourth-party logistics freight management in the food service industry. International Journal of Logistics-Research and Applications, v. 14, p. 1-15, 2013. <https://doi.org/10.1080/13675567.2013.815157>

WANG, X.; PERSSON, G.; HUEMER L. Logistics Service Providers and Value Creation Through Collaboration: A Case Study. Long Range Planning, v. 49, p. 117-128, 2016. <http://dx.doi.org/10.1016/j.lrp.2014.09.004> 